\title{
Faría, la educación colombiana y nortesantandereana*
}

\author{
[Artículos]
}

Campo Elías Flórez Pabón**

Fecha de entrega: 20 de octubre de 2020

Fecha de evaluación: 15 de noviembre de 2020

Fecha de aprobación: 15 de diciembre de 2020

Citar como:

Flórez Pabón, C. E. (2021). Faría, la educación colombiana y nortesantandereana.

Cuadernos de Filosofía Latinoamericana, 42(124).

https://doi.org/10.15332/25005375.6600

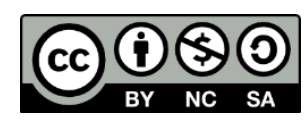

\section{Resumen}

Hablar de educación hoy en día no revela nada novedoso para una sociedad del conocimiento que tiene mil entradas sobre el mismo tema. No obstante, el presente escrito intentará reconstruir qué entendía el filósofo y pensador nortesantandereano José Rafael Faría Bermúdez sobre esta labor a lo largo de los procesos fundacionales que lideró; es decir, desde la creación del Colegio del Norte hasta la creación de la Universidad de Pamplona. Para esto retomaremos tres puntos que construyen su idea sobre educar. Primero, se tomará la pregunta ¿qué es

\footnotetext{
* El presente artículo está vinculado como uno de los avances del proyecto de investigación titulado: "La identidad institucional en el pensamiento de José Rafael Faría Bermúdez", de la Universidad de Pamplona bajo código del proyecto SIGP/Código entidad financiadora PR130-00-003(GA140-CP-II-2014-2.1.2.2.1). Uno de los propósitos de esta investigación es dar a conocer el pensamiento del fundador universitario del Norte de Santander.

** Profesor de la Universidad de Pamplona. Correo electrónico: ceflorez@unipamplona.edu.co; ORCID: https://orcid.org/0000-0003-0443-8432
} 
educar para la vida?; segundo, se analizará la perspectiva con que Faría entendía el papel del estudiante que pregunta con aplomo; y, tercero, se espera responder por qué debemos estudiar con amor. Esto enmarcado desde una metodología descriptiva que apunta a una reconstrucción cualitativa de su pensamiento a partir de sus principales obras.

Palabras clave: educación, educación para la vida, pedagogía del amor, Freire, Faría.

\section{Faría, Colombian and Nortesantanderean education}

\section{Abstract}

Talking about education today reveals nothing new for a knowledge society that has a thousand entries on the same topic. However, this paper will attempt to reconstruct what the philosopher and thinker from Norte de Santander José Rafael Faría Bermúdez understood by this work throughout the foundational processes he led; that is, from the creation of the school Colegio del Norte to the creation of the university Universidad de Pamplona. For this purpose, we will take up three points that build his idea about educating. First, we will question "What is educating for life"; second, we will analyze the perspective with which Faría understood the role of the student who asks questions with aplomb; and third, we hope to answer why we should study with love. This framed from a descriptive methodology that aims at a qualitative reconstruction of his thought from his main works.

Keywords: education, education for life, pedagogy of love, Freire, Faría.

\section{Introducción}

Al hablar del Padre Faría (13 de junio de 1896-17 de diciembre de 1979) nadie pondrá en duda su amor por la educación, no solo porque haya fundado la Universidad de Pamplona, el Colegio del Norte u otros tantos 
entes para la educación en el departamento del Norte de Santander, sino porque él entendía que esta era parte de su misión pastoral como sacerdote, y parte de lo que otorgaba sentido a su labor del día a día; así como el mismo venerable papa Pio XII le hizo saber al ministro nortesantandereano, tal como consta en una misiva que envía el despacho papal el 27 de junio de 1950, donde dice:

Reverendo Presbítero [...] deseoso de contribuir a la formación moral e intelectual de la juventud, ha dado a luz estos libros (curso de filosofía, curso superior de religión y curso inferior de religión), que seguirán haciendo bien a las almas de los que los estudian. (Faría, 1949, p. 4)

No obstante, las cosas no son porque las diga el Papa o su secretario, sino porque así se imponen en los hechos de la vida del fundador de la Universidad de Pamplona, la cual es una de sus grandes obras, pero no la única (Flórez, 2019, p. 18). Por razones obvias podríamos pensar que la obra más importante del fundador es la Universidad de Pamplona, pero esto no le resta valor también al trabajo que empezó como educador en 1936, al escribir bajo el amparo de monseñor Rafael Afanador y Cadena las primeras obras sobre educación religiosa y humanista en el contexto colombiano y nortesantandereano. En estas, él consideraba se debía exponer qué es enseñar. La respuesta a esta pregunta la plasmó en sus diferentes obras, las cuales fueron una apología a la filosofía, la religión, la moral y la sicología que se marcaba en esta época de mediados del siglo XX.

Lo cual podría hacer pensar que, sin este espíritu de educador, Faría Bermúdez no habría tomado la decisión en 1960 de fundar el alma mater para la región nortesantandereana, la cual es la primera Institución de Educación Superior (IES) del departamento, formalmente constituido en 1959, como lo propone Flórez Pabón (2019, p. 18). En otras palabras, sin 
quitar peso de las obras y de la importancia de la Universidad de Pamplona en el Norte de Santander, y en la misma localidad, podríamos afirmar que la obra más importante de Faría Bermúdez es ser educador, lo cual se compagina muy bien con el hecho evangelizador, y posteriormente de allí se desprende la faceta de constructor de aulas donde reposará el conocimiento.

Este hecho nos lleva a cuestionarnos sobre qué está entendiendo en su época el filósofo nortesantandereano por educación y cuál es la labor que debe desempeñar el docente en el proceso de formación de los profesionales que se han acercado a lo largo de la historia a esta IES. Para proponer una respuesta, se retomará lo que expresa en su obra: Curso superior de religión para colegios de segunda enseñanza, allí Faría Bermúdez (1942) expresará que la educación es un hecho que tiene que formar para la vida, donde el pensamiento tiene que perfeccionarse y el cariño tiene que sobresalir frente a lo que debemos hacer: "Educando para la vida, pensando con aplomo, y estudiando con amor" (p. 2). Sin estos tres elementos el trabajo educativo es escueto y no radica en autenticidad en el ejemplo que da el maestro.

De allí que, al mismo tiempo, podamos pensar que la figura del maestro, que encarna el pensador y sacerdote Faría Bermúdez, está implicada con el hecho de la labor pedagógica que se realiza en el aula. Donde el docente ha de estar: "preguntando con aplomo, y respondiendo con amor" (1942, p. 4), hechos que se traducirán en el educando como formación para la vida. Allí hay una conexión entre la teoría que se presenta en el discurso pedagógico y didáctico de la educación y la vida profesional de los egresados. Esto conlleva a construir en el estudiante una identidad la cual refiere al pensamiento crítico, la pedagogía del amor en la labor desempeñada y una conexión entre la vida y la academia. En palabras de 
Theodore Roosevelt: "con los ojos en las estrellas, pero los pies en la tierra".

En tal sentido, podemos decir que la preocupación de la labor educativa de Faría radica en cómo hacerle frente a la vida, en plantearse la cuestión de cómo van a vivir nuestros alumnos si no se les educa, si estos no se preparan profesionalmente para los nuevos tiempos. Razón por la que al llegar de Roma su primer paso fue la fundación del Colegio del Norte en 1953. Ya que tenía inscrita en su mente la necesidad e importancia de prepararnos para el futuro en una pedagogía del amor y con calidad. De allí que en este prestigioso colegio se tuvieran "profesores bien preparados" (Faría, 1942, p. 6), o de alta calidad como don Augusto Ramírez Villamizar y su hermano Joaquín Faría Bermúdez, por mencionar algunos, y es que los profesores bien preparados siempre fue una preocupación del fundador de la Universidad. Ya que creía que en la medida en que estos profesionales sean los mejores, se ofrecerá lo mejor al futuro de la región en la labor educativa. Razón por la que "el profesor no puede improvisarse" (Faría, 1942, p. 7), y debe preparse tanto profesionalmente como en la labor diaria que se imparte en las aulas. Quizá esto de no improvisar, que Faría pregonaba a los cuatro vientos, es la razón por la cual se preocupó tanto por escribir, como se referencia en el texto Curso de filosofía. Cosmología - Ética, Filosofía del comunismo de 1949. Una labor que se perfeccionó día a día, que se mejoró sistematicamente, que se actualizó como consta que sus obras tuvieran hasta siete ediciones del mismo ejemplar, revelando el éxito que esto traía en el modelo educativo que estaba proponiendo en la época. Un modelo que no improvisaba, sino que preparaba la labor del día a día, un modelo que se actualizaba y un modelo que requería de los mejores docentes, cosa que hemos de denominar un llamado a la excelencia. 
Tal espíritu es el que hace que venza miedos, se torne un pionero y al mismo tiempo visionario de la región y opte por nuevos proyectos como es el caso de la fundación de la Universidad de Pamplona. Razón que explica el porqué vendió el Colegio del Norte a los padres españoles del Carmelo en 1959, y partiendo de esto retomó un proyecto intrépido como lo es la fundación de la Universidad de Pamplona el 23 de noviembre de 1960. Sin embargo, retrocedamos a las tres características que fundamentan el pensamiento pedagógico de Faría y profundicemos en lo que el quería hacer como educador.

\section{Educando para la vida}

Según Freire (2004), la educación para la vida es una educación que llama a escuchar la vida y sus reclamos (p. 6). No porque Faría hubiera citado al recifense, sino porque en este sentido se conectan los dos pensadores.

Rescatan de forma actualizada, leve, creativa, provocativa, valerosa y esperanzadora, cuestiones que continúan día a día instigando el conflicto y el debate de educadores y educadoras. Lo cotidiano del profesor en el salón de clases y fuera de él, desde la educación elemental hasta el posgrado, es explorado como en una codificación, en cuanto espacio de reafirmación, negación, creación, resolución de saberes que constituyen los contenidos obligatorios de la organización programática y el desarrollo de la formación docente. Son contenidos que sobrepasan los ya cristalizados por la práctica escolar y de los cuales el educador progresista, principalmente, no puede prescindir para el ejercicio de la pedagogía de la autonomía aquí propuesta. Una pedagogía fundada en la ética, en el respeto a la dignidad y a la propia autonomía del educando. (Freire, 2004, p. 6)

Ante esto, pueden increparme y decir que esto no es propio al pensamiento de Faría y que él no habla de esto en sus textos. Lo cual pretendo afirmar. 
Tal como lo hemos visto, ese espíritu cotidiano del profesor en el salón de clases y fuera de él es lo que Faría Bermúdez afirma cuando se presenta la preocupación por educar para la vida, idea que lo cosntruye como visionario al proponer el secretariado bilingüe y la asistencia social como primeros programas a ofertar en el alma mater. Posteriormente, "Matemáticas, Química, Biología, Ciencias Sociales, Pedagogía, Administración Educativa, Idiomas Extranjeros, Español - Literatura y Educación Física”, como Valero Álvarez y Pulido (1999) y Puerto, (2018) nos comentan en sus textos.

Pero, qué significa la implementación en la decada del sesenta y setenta de estos programas si no el deseo de formas profesionales que generen progreso y una autonomía para la región, con ese tinte de licenciaturas que revelan su interés por la educación. Se hace así de los saberes de las ciencias básicas y licenciaturas un espacio de codificación, en cuanto espacio de reafirmación, negación, creación, resolución de saberes que constituyen los contenidos obligatorios de la organización programática y el desarrollo de la formación docente. Es decir, una mirada que apunta por su carácter a la profesionalización de quienes se han inscrito para el desarrollo de la región y el país, y por el otro presenta una reflexión sobre el desarrollo de la práctica de la formación docente, en la cual hay unos contenidos que sobrepasan los ya cristalizados por la práctica escolar y de los cuales el educador progresista se proyecta. De ahí que pase de formar en un colegio a formar profesionales con sentido ético en alto grado, lo cual compaginaría con esta pedagogía ética de dignidad de Freire.

En este sentido, para Faría la ética tiende a un fin determinado, en este caso la educación y una que aporte para la vida, y qué mejor elemento que la ética para que esto se dé. Pues, si no tiene un fin propio y deliberado provocará una actuación que no será útil, deleitable y honesta (Faría, 1949, p. 160). De allí que todo ser que tienda al bien, y como bien puede 
interpretarse el docente y su labor, para que obren en un fin que va más allá de él, y que tenga un carácter más sublime que el egoísmo. En tal sentido plantea lo siguiente:

Puede el hombre obrar algunas veces sin proponerse explícitamente un fin determinado; pero cuando obra humanamente, con voluntad deliberada, no puede menos de proponerse un fin, y es precisamente el dirigirse a un fin deliberado lo que lo hace dueño de sus actos y responsable de ellos. (Faría, 1949, p. 161)

Este comentario concuerda plenamente con la tesis freireriana de la autonomía y dignidad. La cual expresa "una pedagogía fundada en la ética, en el respeto a la dignidad y la propia autonomía del educando" (Freire, 2004, p. 6). Así mismo, este deseo de formarnos éticamente en perspectiva de autonomía revela la importancia de la consecusión de un fin, lo que se propone con la actividad humana y más con la docente. De allí no ha de causarnos extrañamiento pensar en formar profesionales para la vida, pero con una vida ética, donde la ciencia se proponga como rectora de la actividad humana. Pues como precisa Faría: "Si el hombre no consigue su último fin, su naturaleza quedará trunca y su destino frustrado; y por tratarse de una criatura racional y responsable de sus actos, el resultado será su infelicidad definitiva” (Faría, 1949, p. 161). Idea que se opone a la felicidad, o gusto por lo que hacemos, o hacia lo cual estamos llamados como docentes, ya que se es docente no por placeres, riquezas, fama u honores. Se es docente porque esto causa nuestra felicidad o el bien supremo en nuestra acción. Si tuvieramos placeres, riquezas, fama u honores estariamos inestables y con conciencia de que se pueden perder, con excepción del mérito y la virtud que desaparecen con la muerte (Faría, 1949, p. 164). 
En otras palabras, estamos llamados a una labor docente que se fundamente en el mérito y la virtud de nuestras acciones en sentido ético y autónomo, que procure la dignidad del educando y del educador, que mire el obrar y la necesidad de quien vamos a formar. Pues muchas veces formamos, pero no nos preguntamos ¿̇cómo será el actuar profesional de aquel que hemos formado?, ¿cómo será su vida?, ¿cómo hemos contribuido a esto?, si hemos ayudado a construir un ciudadano ético y virtuoso, lleno de méritos o simplemente hemos contribuido con uno del montón que quizá aporte más a los vicios que a construir el ideal que queremos. Con esta reflexión pensemos en el segundo factor, que habla de nuestra capacidad racional.

\section{Pensar con aplomo}

Pensar para Faría se refiere a la seriedad del pensamiento; es decir, cómo estamos realizando nuestra labor para que el alumno adquiera esta madurez requerida en sus reflexiones. Aclaramos que el padre Faría no solo refiere esto a las cuestiones religiosas o filosóficas, sino a las que tienen que ver también con la ciencia y con las licenciaturas. Ya hemos dicho que para esto debemos tener el mejor perfil profesional que se pueda tener, es decir, profesionales idóneos y no improvisados que puedan realizar su labor de la mejor manera posible. Para esto pone como ejemplo a don Augusto Ramírez Villamizar y de su hermano Joaquín Faría Bermúdez, figuras que presentan esa idoneidad requerida y ejemplar para la labor educativa. No obstante, vamos a recapitular en la figura de don Augusto Ramírez Villamizar, poeta, periodista, docente y erudito historiador como lo refiere su hija María de Lourdes en el centenario de su muerte. Para Faría este era el modelo de docente, aquel que sería capaz de ayudar a madurar el pensamiento de los discípulos. Pero por qué esta nominación. 
Fue Augusto trabajador infatigable, estudioso de la historia, que en el pensamiento de Cervantes "es la émula del tiempo, depósito de las acciones, testigo de lo pasado, ejemplo y aviso de lo presente, advertencia de lo por venir”. Varias instituciones académicas registran con orgullo haberlo contado entre sus más destacados miembros. (Gavassa, 2012, párr. 2)

Actitudes que lo proponen como un modelo de educador. Según comenta Gavassa (2012) en entrevista a la hija de don Augusto Ramírez Villamizar, el cual fue profesor de los colegios de la Comunidad de las Hermanas Betlehemitas, del Colegio de las Hermanas Dominicas Terciarias, de La Normal de Varones, del Seminario Menor Santo Tomás de Aquino de Pamplona y, por supuesto, del Gimnasio del Rosario. Coofundador y colaborador de las revistas Aulas de la Normal Superior de Varones de Pamplona, Excelsior del Colegio del Sagrado Corazón de Jesús, Norte y Sur, editada en Bucaramanga y de la revista Educación del Norte de Santander, órgano de divulgación del Gobierno departamental. Corresponsal de varios periódicos de la región y de Santander, entre ellos Comentarios y Diario de la Frontera de Cúcuta. El Frente y Vanguardia Liberal de Bucaramanga y fundador y director de la revista Semana Santa en Pamplona, órgano anual de divulgación de la Asociación de Amigos de Pamplona. Fue coofundador de la Universidad de Pamplona con su amigo el Padre Rafael Faría Bermúdez. Fundador del grupo de teatro experimental La Herradura de Oro.

Además, fue el ganador del Primer Premio en Poesía de los Juegos Florales con motivo del sesquicentenario de Pamplona, con su hermoso "Romance del Santo Cristo del Humilladero" (Ramírez, 1976, p. 79). Don Augusto, según narra su hija María Lourdes en nota de presa, realizó las siguientes obras: 
Fundó y condujo acertadamente la Asociación de Amigos de Pamplona, destacándola como una entidad cívica al servicio de la comunidad pamplonesa y del departamento. Con su gestión renació y se consolidó la Semana Santa de Pamplona, ocupando el lugar que le correspondía en el ámbito nacional, por la belleza de sus imágenes y el fervor cristiano de los habitantes del valle del Espíritu Santo ${ }^{1}$ y sus visitantes. Fue su presidente hasta su muerte. Nombrado Cónsul de la Escuela Militar de Cadetes, siendo su representante en el Norte de Santander. Perteneció a la Academia de Historia del Norte de Santander y a la Academia de Historia de Santander. Fue nombrado Caballero de la Orden de Malta y Caballero del Santo Sepulcro. Motivó al Gobierno nacional y al departamental en compañía de su obispo amigo, Rafael Sarmiento Peralta, para la construcción de los museos que hoy son orgullo y monumentos de Pamplona. El Gobierno nacional, el departamental, el eclesiástico y el de su terruño, reconocieron su labor tanto educativa como cívica y fue exaltado con sus más destacadas condecoraciones. José Eusebio Caro en grado extraordinario. (Dos veces), Eduardo Cote Lamus, Vaticano Segundo, Alcalde Acevedo. (Balmaceda, 2012, párr. 25)

Virtudes que Faría respetó y aplaudió. Ese amor por las humanidades del padre Faría estan inscritas en su amigo Ramírez Villamizar. Esa capacidad de no improvisación y de aplomo están propuestas en la actitudes de busqueda de "Lo esencial que son las ideas" (Faría, 1942, p. 11). Esto es lo que preocupa a Faría, pues el alumno debe buscar la esencia de las doctrinas para que este las exprese correcta y claramente, en esto consistirá pensar con aplomo, corresponderse con lo que se ha estudiado. Pues si hay objeciones frente a lo aprendido, "las objeciones se pulverizan [...] cuando la verdad sale a su encuentro" (Faría, 1942, p. 13). Cuando se

\footnotetext{
${ }^{1}$ Valle del Espíritu Santo es uno de los tantos nombres que se le han dado a la ciudad de Pamplona, en Norte de Santander, Colombia. Urbe donde el filósofo nortesantandereano desarrolla gran parte de su actividad intelectual a lo largo de su vida hasta su muerte en 1979.
} 
hace un estudio serio y concienzudo de la materia a trabajar. Es que para Faría es importante tener claro lo que se quiere estudiar, las herramientas propuestas de una manera seria, pues esa será la manera como se enfrentará el profesional al futuro. De qué otra forma si no es así: "los verdaderos derechos del niño no son los derechos a una libertad necia, de la cual uno no sabe qué uso debe hacer, sino a una educación temprana y completa” (Faría, 1949, p. 240). Idea que después cristalizará en la educación de la juventud en la universidad que se fundará.

Para él, la universidad debe ofrecer con exactitud los conceptos que define, un orden riguroso en la repartición de la materia general y particular dentro del plan que oportunamente trazaron los encargados de la educación en Colombia y, por último, una adaptación de la asignatura a las condiciones actuales (Faría, 1942, p. 14). De allí que podamos decir que la obra de Faría es una obra educadora con un tinte pedagógico claro, exacto y actualizado para que se genere en el alumno un proceso de madurez en el pensamiento (Faría, 1940, p. 13), que conduzca a la verdad y no al error de doctrinas extrañas que puedan desviar del camino correcto al alumno. Lo cual nos lleva al tercer punto que queremos exponer, el cual habla del amor.

\section{Estudiar con amor}

Lo primero que se debe decir respecto a la perspectiva del amor en la obra de Faría es que es amplia y fruto de su labor docente. Como se evidencia en varios de sus escritos Del libro amor, y Amor y matrimonio, (Jiménez y Andersson, 2019, p. 57). Lo cual permite entender que Faría fue un verdadero amigo de Dios y de los hombres, "a quienes favorecía en nombre de la doctrina del amor" (Barriga, 2002, p. 93). Esta parte de la esencia de lo que es Dios según la escrituras en Juan 4:7-9: “Amados, amémonos 
unos a otros; porque el amor es de Dios. Todo aquel que ama, es nacido de Dios, y conoce a Dios”.

Tal presencia de Dios en el filosófo nortesantandereano hacen que poetise la vida y la contemple con una mirada mística y reflexiva, como aclara Jaimes (2015): "Padre Faría, poeta de la vida cotidiana y de la angustia mística. Cantor del amor en todas sus dimensiones, Gran amigo y consejero" (p. 3). Fue, además de todo, quien en todo momento habló del amor, incluso en la educación como motor que alimenta la labor pedagógica. Por lo cual dió gran importancia a este sentimiento en la labor por parte del alumno. En otras palabras, no solo expuso cómo debía ser el maestro, sino también el estudiante. Este debía tener la virtud de amar lo que hacía, como aquel que gusta de la filosofía (amor por la sabiduría), tenía que estar inscrito en un gusto por el conocimiento, como lo asegura el matemático Pitágoras en la antigüedad (Flórez-Pabón, 2020, p. 5).

Porque a todos nos corresponde tener una serie de disposiciones, y más al alumno cuando debe prepararse para la vida. No obstante, a este amor por las letras ha de acompañarle cierta libertad en la toma de decisiones, cosa que le dará una ética en su actuar. Decía Faría: “A los alumnos les corresponde cierta libertad en la determinación de la materia" (Faría, 1942, p. 11). Pero, les corresponde esto y nadie se lo debe prohibir, es decir, su libertad para determinar qué estudiar y para amar lo que se estudia. Solo así se forman ciudadanos útiles, como se dirá hoy, con un pensamiento crítico. Que puedan ayudar a construir una mejor región, una mejor ciudad y un mejor país.

Posterior a esta determinación y amor, Faría siempre insistió en que habría algunas cosas que se enseñaban a los alumnos que estos mismos no comprendían, en el sentido de por qué eran enseñadas. A lo cual respondía que: "Aunque no se pueda ver todo, todo es útil, y puede servir más tarde provechosamente" (1942, p. 10). Es decir, el currículo que se enseña está 
pensado para el devenir profesional, ese futuro para el que se debe formar. El alumno, aunque no entienda hacia dónde apunta los contenidos que se enseñan, en el pensamiento de Faría (1942), convergían en que todo le sería útil al alumno de uno o de otro modo. Reevaluando, lo que los mismos estudiantes dicen hoy, respecto de las asignaturas mal llamadas de relleno. En fin, todo aporta a que se llegue a la madurez del pensamiento, todo aporta al proceso formativo desde esta perspectiva, y más si se hace con amor en la práctica pedagógica en las aulas y fuera de estas. Esta será la visión de formación integral en el pensamiento de Faría, la cual habla de un punto holístico de la formación, el cual es incluyente en todas las partes del proceso formativo.

Lo anterior nos lleva a reflexionar en la obra más famosa de Faría en la década del cuarenta en la educación colombiana, la cual es Curso superior de religión (1942). Esta, con su carácter de tratado apologético, presenta ideas importantes y bien estructuradas las cuales ayudan a proponer la perspectiva de la pedagogía del amor en el filósofo. No obstante, este no fue el único texto importante, pues después publicó Del libro amor (1943). Aquel amor que construye una pedagogía, pero produce en el alumno un cambio de perspectiva, la cual está enfocada en el amor por el estudio (filosofía). A su decir: "el libro amigo y consejero que, a través de la existencia, nos interesa poner en sus manos" (Faría, 1942, p. 9), es siempre eso un amigo, y nosotros respecto de él debemos tener amor. Algo semejante a lo que Freire propondrá en su obra Pedaogy of the heart (2000).

Pero qué significa pensar en esta pedagogía que aboca el sentimiento, para esto me permitiré citar otra vez a Freire en la Pedagogía del oprimido (2013), cuando habla que tal hecho propone una educación bancarizada que nos aleja de lo que realmente sería la pedagogía del sentimiento, como ha expresado Faría en sus textos; sin embargo, al incurrir en el error de 
una mala hermenéutica del amor estarían también confluyendo con el pensamiento de Freire; es decir, en su ansia insaciable. En ella, el educador aparece como agente indiscutible, como real sujeto, cuya tarea irrenunciable es la de llenar a los educando o alumnos de los contenidos de su narración. Contenidos que son retazos de la realidad del estudiante, desconectados del contexto como totalidad en la que se engendran y en cuya visión ganarían significado. La palabra, en estas exposiciones, es vacía de la dimensión concreta que debería tener o ser transformada en falsas palabras, en una verbosidad alienada y alienante. De ahí que sea más sonido que significación y, así, sería mejor no decirla. Esto es una educación bancarizada (Freire, 2013, p. 43).

En pocas palabras, como Faría lo expresaría en sus textos en donde se trata el socialismo, se nos quería prevenir de esta realidad. En tal sentido, para entender la educación de las emociones en el estudiante, era preciso recordar el concepto de educación bancaria, una concepción de la educación como proceso de depositar los contenidos en el alumno por el educador donde se mal interpreta constantemente el sentimiento y se hace de la pedagogía del amor o del sentimiento como algo soso, algo lleno de sentimentalismo y lo grave es que allí se queda. Pues este tipo de educación no es liberadora, porque se incurrió en el error y, de alguna forma, también nos oprime. En cambio, la educación debe ser un proceso formativo integral que gire en torno de la comunicación y el diálogo. En contraste de la educación bancaria de intereses sosos que contempla al educando como sujeto pasivo, ignorante que ha de memorizar y repetir los contenidos que se le inculcan por el educador, poseedor de verdades únicas e inamovibles.

Así, el alumno nunca tendrá amor por los libros y menos por la educación que se le imparte. Es allí donde Faría, como Freire, señalan que el educador ha de partir del nivel individual, cultural, político, económico, 
social, en el que el educando se encuentra, con el objetivo de respetar sus límites individuales y transformar ese mundo. Solo así, se podrá concebir la educación como una obra de arte y el educador como un artista que rehace el mundo, lo redibuja. Un artista que lo hace desde la sensibilidad, desde la estética, la ética y se privilegia la libertad; con su voz que no tiene sentido sin la voz del grupo y al entender que el amor es la transformación definitiva y que la única forma de enseñar a amar lo que se hace es amando (López, 2011). Como propone Cabeza y Velasco en su texto: "Si no hay amor, si no nos movemos en el amor en nuestros encuentros con otros, no hay fenómeno social, y la opción es la indiferencia que permite cualquier mecanismo de negación del otro, desde la competencia al odio" (Cabeza y Velazco, 2011, p. 170). Esto deshumaniza el acto de educar en el amor como pretendía Faría, al ver en el otro, en el alumno ese prójimo a quien se ama a través de la labor educativa que transforma la vida y el pensamiento.

\section{Consideraciones finales}

Finalmente, hemos de considerar que solo se llegará a educar para la vida, a pensar con aplomo y a estudiar con amor cuando consideremos el significado de qué es educación con espíritu crítico, por lo menos desde la perspectiva de Faría Bermúdez, y de la de Freire, a quien hoy queremos equiparar. Ya que el significado de la educación crítica de Freire, en una sociedad con una cultura de capital, haría que los neoliberales no estuvieran dispuestos a asumir el riesgo de enfrentarse a una cultura en la cual las redes emergen de la construcción crítica de conocimientos, los cuales probablemente desarrollarían una nueva cultura del capital. Esto es lo que prevé Freire, y aquí es donde los neoliberales se retiran frente a este problema eficaz, inclusivo, democrático que es la educación, la cual se debe resolver (Freire, 2000, p. 18). 
Ahora, en el contexto colombiano, cómo resolver el problema de la educación a la que nos enfrenta Freire en nuestras sociedades neoliberales y tecnologizadas (Flórez y Acevedo, 2020, p. 1), pues tanto ayer como hoy sigue siendo necesario tener y crear una pedagogía crítica en la sociedad, y una pedagogía que hable de lo práctico de la labor docente, no alejada de la realidad, no para que copie modelos, sino para que los recree y haga del quehacer diario en la educación un reto para el docente y el estudiante. En palabras de Faría, sería como buscar esto con "pedagogía, razón, y amor que nos educan para la vida” (Faría, 1942, p. 8). Esta sería la manera de entender la educación colombiana y nortesantandereana en las décadas de 1940 a 1960, según la perspectiva de un pensador criollo.

\section{Referencias}

Balmaceda, A. P. (2012, octubre). Unipamplona conmemoró 100 años del nacimiento de Augusto Ramírez Villamizar.

Unipamplona.edu. http://www.unipamplona.edu.co/unipamplona/portalIG/hom e 1/recursos/noticias-2012/octubre/17102012/augusto ramirez villamizar.jsp

Barriga, I. A. (2002). Personalidades artísticas, culturales y científicas del Norte de Santander. Universidad de Pamplona.

Cabeza, O. y Velazco, Z. (2011). Mirada desde los estudios culturales CTS a la educación y desarrollo humano en el marco del centenario del Departamento Norte de Santander. Temas, 3(5), 161-172. https://doi.org/10.15332/rt.voi5.692

Faría Bermúdez, J. R. (1940). Curso inferior de religión para los años primero y segundo en colegios de segunda enseñanza. Editorial Voluntad.

Faría Bermúdez, J. R. (1942). Curso superior de religión para colegios de segunda enseñanza (7 ed.). 1942.

Faría Bermúdez, J. R. (1943). Del libro amor. Editorial Voluntad.

Faría Bermúdez, J. R. (1949). Curso de filosofía. Cosmología, ética, filosofía del comunismo (2 ed.). Editorial Voluntad. 
Flórez Pabón, C. E. (2019). Faría: marxismo y comunismo. Cuadernos de Fỉlosofía Latinoamericana, 4O(121), 17-30. https://doi.org/10.153332/25005375.5468

Flórez-Pabón, C. E. (2020, March). Nuances of the philosophy of mathematics. Journal of Physics: Conference Series, 1514, 012029. https://doi.org/10.1088/17426596/1514/1/012029

Flórez-Pabón, C. E., y Acevedo-Rincón, J. P. (2020). Experiences of University education in virtuality in the public and private context in Colombia. Olhar de Professor, 23, 1-4. https://doi.org/10.5212/OlharProfr.v.23.2020.15577.209209225596.0528

Freire, P. (2000). Pedaogy of the heart. Continuum.

Freire, P. (2004). Pedagogía de la autonomía. Paz e Terra.

Freire, P. (2013). Pedagogia do oprimido. Paz e Terra.

Gavassa Villamizar, E. (2012, 6 de noviembre). Augusto Ramírez Villamizar. Vanguardia https://www.vanguardia.com/opinion/columnistas/edmundo-gavassavillamizar/augusto-ramirez-villamizar-ITVL181922

Jaimes Gómez, M. (2015, 23 de noviembre). José Rafael Faría Bermúdez: el hombre, el educador, el apologista y el fundador.

Unipamplona.edu. http://www.unipamplona.edu.co/unipamplona/portalIG/home _1/recursos/noticias_2015/noviembre/23112015/nota faria.pdf

Jiménez, C., y Andersson, O. (2019). Manuales escolares y libros de texto de filosofía escolar en Colombia 1945-1979 [Tesis de maestría]. Universidad Pedagógica Nacional.

López A. J. (2011, 22 de enero de 2011). La competencia emocional. La competencia emocional.blog.

https://lacompetenciaemocional.blogspot.com/2011/01/paulo-freire.html

Puerto, C. F. P. (2018). Filosofía, literatura y pedagogía. Cuadernos de Filosofía Latinoamericana, 39(118), 9-12. https://revistas.usantotomas.edu.co/index.php/cfla/article/view/4862/4582

Ramírez, A. (1976). Efigies. Ediciones JEAL.

Valero Álvarez, M. y Pulido Castellanos, F. (1999). Presbítero José Rafael Faría Bermúdez. Fundador de la Universidad de Pamplona.: Universidad de Pamplona. 